\title{
A Study on Finite Element Analysis of Electric Bus Frame for Lightweight Design
}

\author{
Zhuo Yang ${ }^{1}$, Baoqing Deng ${ }^{1, a}$ Mengqi Deng ${ }^{2}$ and Gongrui Sun ${ }^{1}$ \\ ${ }^{1}$ Department of Mechanical and Automotive engineering, Zhuhai College of Jilin University, Zhuhai, China \\ ${ }^{2}$ School of Automotive Studies, Tongji University, Shanghai, China
}

\begin{abstract}
The air pollution becomes a risk to health with the increasingly growing of car ownership in China. Due to the increase of energy crisis and environmental pollutant, the electric vehicle is becoming a promising transport in the urban area. However, the drawback of the electric vehicle lies in the endurance of the vehicle battery. Therefore, the lightweight design which adopts both the structural steel and the aluminum alloy can reduce the weight of the vehicle body extending the battery life between charges. In this paper, we used a finite element analysis (FEA) method for the lightweight optimization of the electric bus frame. Four driving condition (full load bending condition, torsional condition, emergency braking and emergency steering) were considered for the analysis. By changing the structure of bus frame, the weight of the bus reduced while the mechanical property improved under the adopted driving condition.
\end{abstract}

\section{Introduction}

The air pollution is becoming a serious problem because of the vehicle emission although more critical emission standard is already in force [1,2]. Apart from the air pollution, the noise pollution which is produced by vehicle in urban area also impairs the sustainable development of a city [3]. Therefore, electric vehicles have been paid much attention due to its characteristics of zero-emission and lower noise pollution. However, there are some drawbacks of the electric vehicle. The biggest problem lies in the battery life between charges. In addition, the charging time and the number of the electric vehicle infrastructure in China limit the spreading of the electric vehicle. The lightweight design of the electric vehicle is a compromise method which can extend the battery life between charges. In addition, the weight reduction of vehicle body which is pursued by most automotive manufacture can meet the requirement of reducing production cost and improving fuel efficiency of petrol powered vehicle [4]. This is the first time that using FEA to analyze the static force on the electric bus for the lightweight of the electric bus. In this paper, we developed a three-dimension model of an electric bus frame which is based on the material of structure steel and aluminum alloy. Then we used FEA method to conduct the static analysis which is based on four driving conditions. According to the results, we reduced the weight of the bus roof by changing the installation position of the battery and reducing the cross-sectional width of the frame on the roof.

\section{3D Model of electric bus frame}

In this study, due to the requirement of lightweight design, the frame of the electric bus adopted both structural steel and the aluminum alloy. The chassis and the connector of the chassis is made by the structural steel to guarantee the strength requirement while the pillar and the roof is made by the aluminum alloy to reduce the mass of the vehicle body. The stress-strain curve for the two materials are shown in Figure1 and Figure2, respectively.

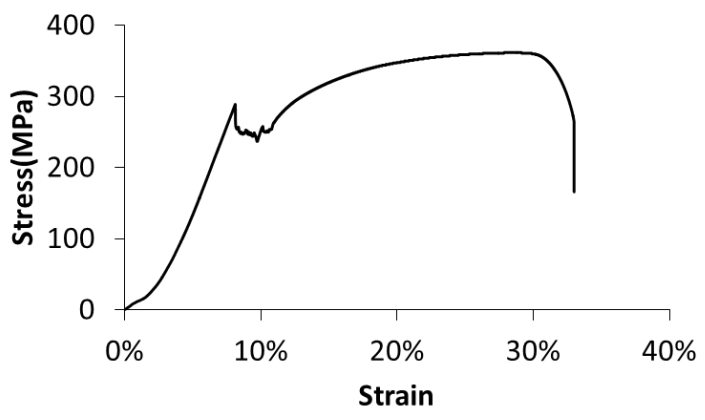

Figure 1 Stress-strain curve for structure steel

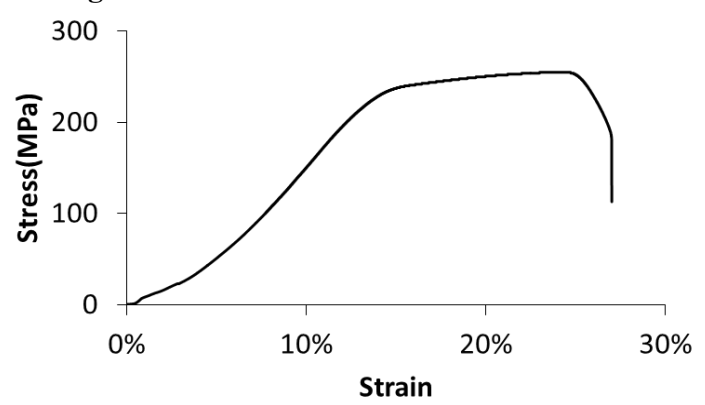

Figure 1 Stress-strain curve for aluminum alloy 
We used the SolidWorks for the generation of a detailed body geometric model of the bus (Figure3). The size of the bus is $12 * 2.5 * 2.7 \mathrm{~m}^{3}$. The chassis of the bus is welded by structure steel and the skeletons of the vehicle body are made of aluminum alloy. The connection of the chassis and vehicle body is finished by bolt connection. To simplify the FEA process, we simplify the threedimension model by neglecting the non-bearing components such as the windows of the bus. In addition, we simplify the cross-section shape of the components and omit the fabrication holes of the vehicle body, which can be a benefit to the mesh generation in FEA.

Table 1 weight distribution of the electric bus

\begin{tabular}{cc}
\hline & Mass $(\mathrm{kg})$ \\
\hline Bus frame & 4112 \\
Passenger and chair & 5451 \\
Battery at the end & 568 \\
bus side battery & 200 \\
The battery on the & 1171 \\
roof & 170
\end{tabular}

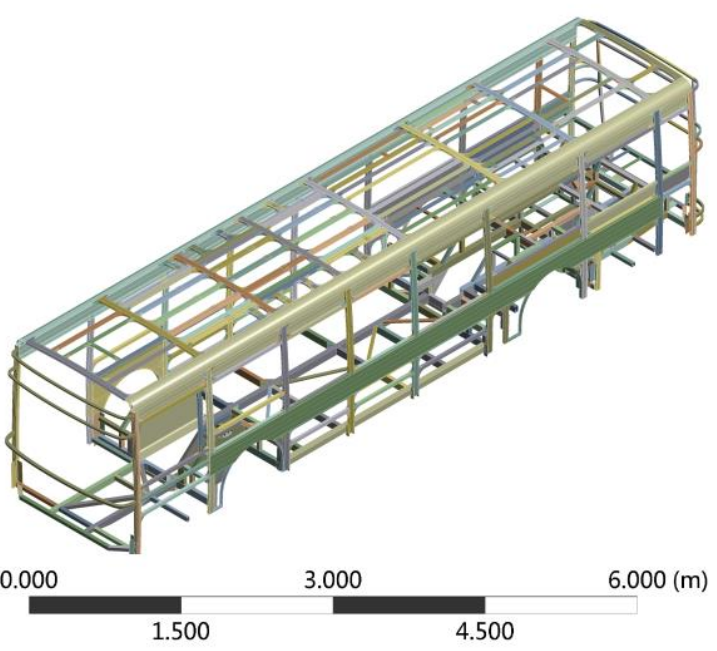

Figure $2 \mathrm{CAD}$ model of the bus frame

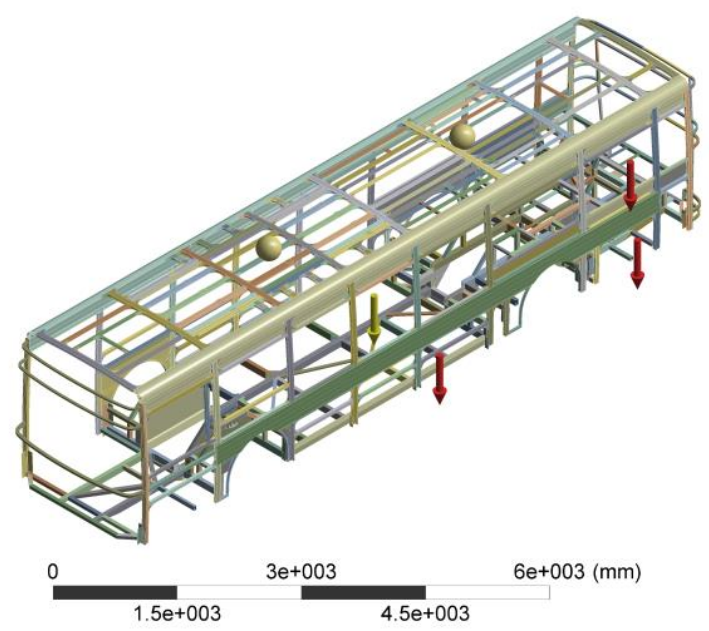

Figure 3 Force load for the full load condition
ANSA (SA Kato Scholari, Thessaloniki). It has 726121 elements. These consist of 710179 quadrilateral elements and 11719 triangular elements

The mass of the electric vehicle is consisted by vehicle frame, passenger and chair, battery, and air condition. The weight distribution of the electric bus during full load condition is shown in Table1. As shown in Figure4, the air condition and the battery on the roof of the bus exert a concentrated load while the bus side battery, passenger and chair, and battery at the end of the bus give a uniformly distributed load.

In this study, four driving conditions were considered which were full load bending condition, torsional condition, emergency braking and emergency steering. The full load bending condition was the most frequent case in normal use of the vehicle which the self-weight, assembly parts and passenger weight are the main bending load. We assumed that the passenger mass is set to be $65 \mathrm{~kg} \times 70=4550 \mathrm{~kg}$. In the full load bending mode, by conducting the rigidity analysis, the largest deformation was $15.189 \mathrm{~mm}$ which located at the location of the battery on the roof. Then we also analyzed the strength of the model and the largest stress (191.62MPa) was the welding components which connected the chassis and the air suspension of the right front wheel. The deformation and the stress are shown in Figure5.
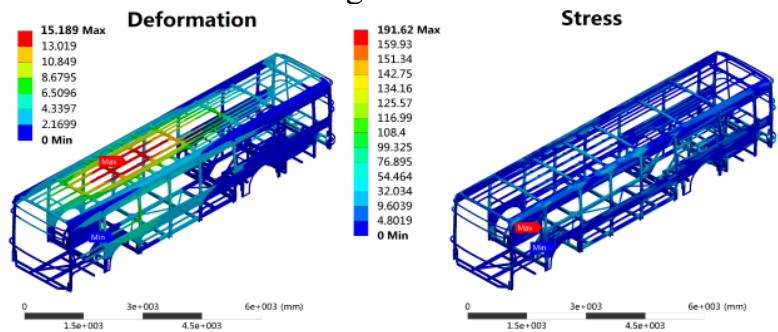

Figure 4 The deformation and the stress under the full load bending condition.

The torsional condition resulted from large stress in a bus body, which was simulated by letting the front left wheel off the ground [5]. The passenger mass for the torsional condition was also set to be $4550 \mathrm{~kg}$. As is shown in Figure6, the largest deformation is $19.331 \mathrm{~mm}$ which is still located on the roof of the bus where the battery is installed. For the torsional condition, we inspected the deformation rate of the frame beam of the side window and the door which are shown in Table2.
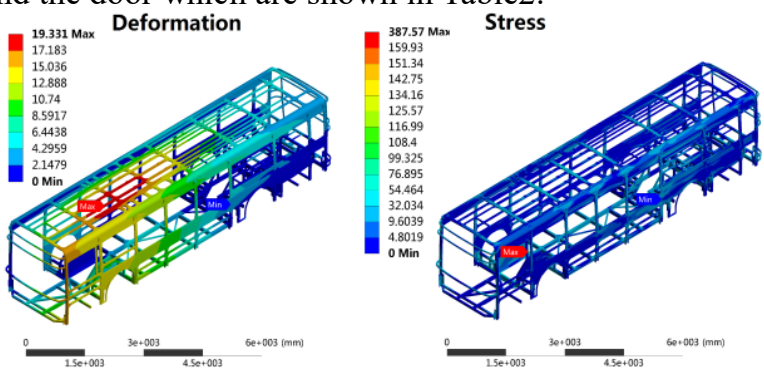

Figure 5 The deformation and the stress under the torsional condition.

\section{FEA of the electric bus frame}

The mesh generation of the bus frame is completed by the 
Table 2 Deformation rate of the frame beam of the windows and the door under torsional condition.

\begin{tabular}{lclc}
\hline \multicolumn{1}{c}{ Position } & $\begin{array}{c}\text { Deformation } \\
\text { rate }\end{array}$ & Position & $\begin{array}{c}\text { Deformation } \\
\text { rate }\end{array}$ \\
\hline Right door 1 & 0.03 & Left window 1 & 0.03 \\
Right window 1 & 0.04 & Left window 2 & 0.05 \\
Right window 2 & 0.09 & Left window 3 & 0.09 \\
Right window 3 & 0.04 & Left window 4 & 0.14 \\
Right door 2 & 0.02 & Left window 5 & 0.16 \\
Right window 4 & 0.01 & Left window 6 & 0.04 \\
\hline Right window 5 & 0.05 & Left window 7 & 0.03 \\
Right window 6 & 0.07 & Left window 8 & 0.05 \\
\hline
\end{tabular}

In the emergency brake condition, the loadings of the bus are the same as the full load bending condition and the torsional condition. In addition, we give a $0.7 \mathrm{~g}$ deceleration to the bus in the longitudinal direction. The rigidity and the strength analysis are shown in Figure7. The largest deformation $(16.647 \mathrm{~mm})$ still located at the battery position on the bus roof while the largest stress $(320.59 \mathrm{MPa})$ is at the support of the air suspension.
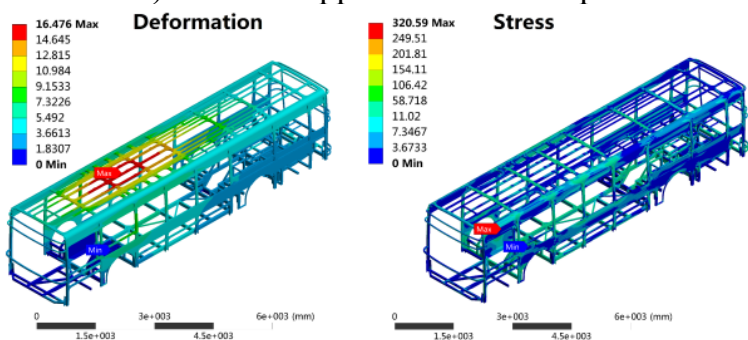

Figure 6 The deformation and the stress under emergency brake condition.

The last driving condition is the emergency steering condition which has the same loading as the full load bending condition. Additionally, we gave a $0.4 \mathrm{~g}$ acceleration to the lateral direction of the electric bus. The analysis is shown in Figure 8. The largest deformation $(38.228 \mathrm{~mm})$ still located at the battery position on the bus roof while the largest stress $(472.28 \mathrm{MPa})$ is at welding component beneath the.front door where connected the bus frame and the chassis.
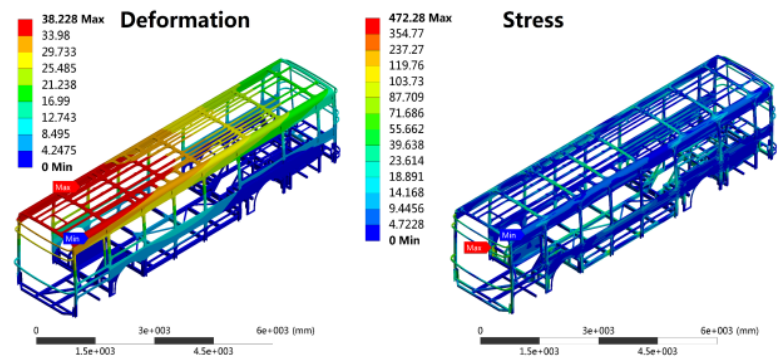

Figure 7 The deformation and the stress under emergency steering condition.

As the results shown above, the problem lay in the unreasonable distribution of the battery on the bus roof. According to the position where largest deformation and strength occurs, we optimize the structure of the bus frame as follow.

1. Transfer the battery from the roof to the chassis of the electric bus which is shown in Figure 9.

2. Reduce the reinforced ribs on the roof of the bus and reduce the thick of the frame on the bus roof from $4 \mathrm{~mm}$ to $3 \mathrm{~mm}$.

3. To guarantee the strength of the chassis, the frames which are used to support the battery were thickened from $6 \mathrm{~mm}$ to $12 \mathrm{~mm}$ (Figure 9).

The total weight of the bus frame reduced $212 \mathrm{~kg}$
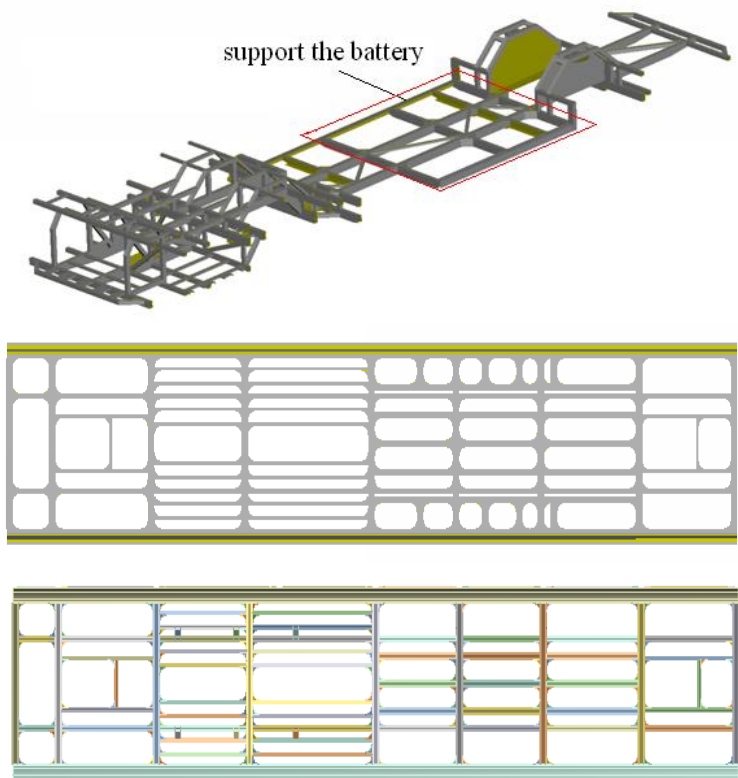

Figure 8 Modification of the structure of the electric bus frame

After the modification, we used the FEA method to analyze the modified bus frame under the same conditions and the results are shown from Figure10 to Figure13, and Table3.

Table 3 Deformation rate of the frame beam of the windows and the door under torsional condition after modification of the bus frame structure.

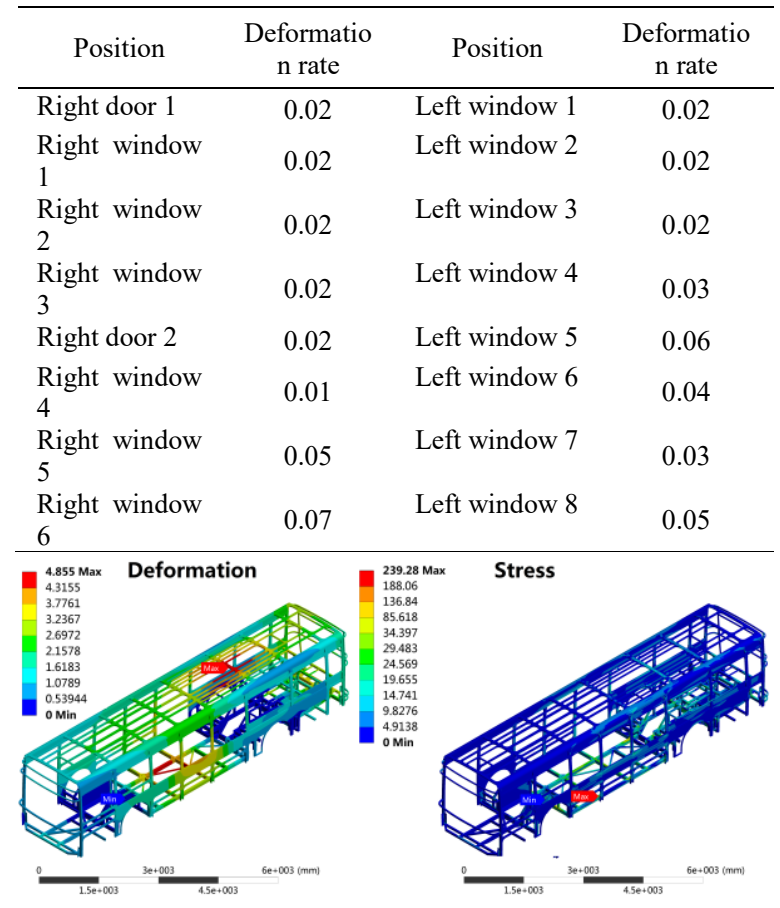

Figure 9 The deformation and the stress under the full load bending condition after modification of the bus structure. 


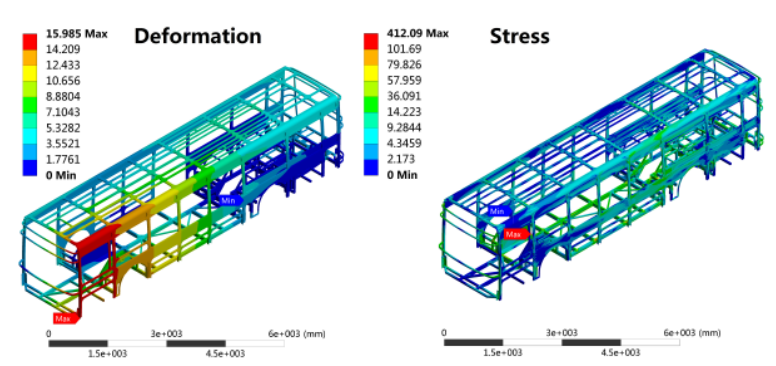

Figure 10 The deformation and the stress under the torsional condition after modification of the bus structure.
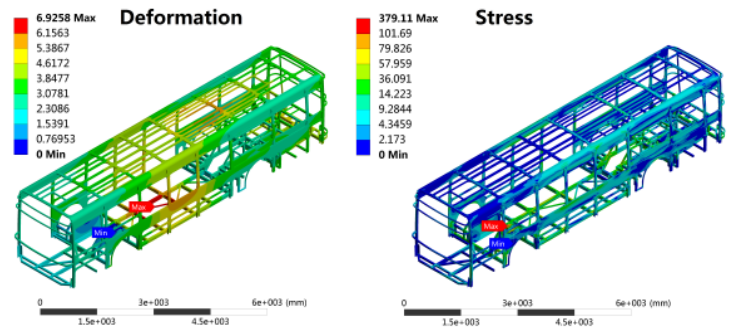

Figure 11 The deformation and the stress under the emergency brake condition after modification of the bus structure.

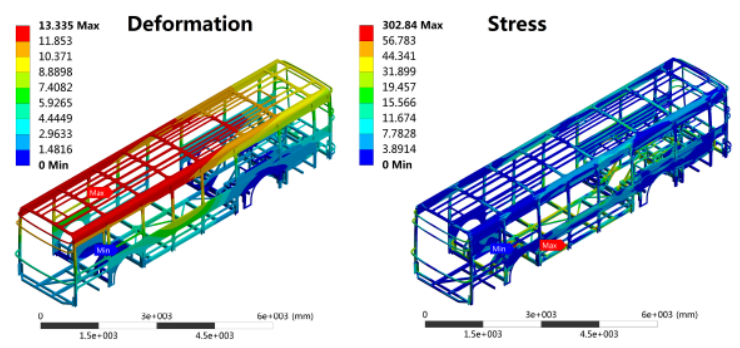

Figure 12 The deformation and the stress under the emergency steering condition after modification of the bus structure.

Table 4 The comparison of stress and deformation before and after modification of electric vehicle structure

\begin{tabular}{ccccc}
\hline & \multicolumn{2}{c}{ After modification } & \multicolumn{2}{c}{ Before modification } \\
& $\begin{array}{c}\text { Stress } \\
(\mathrm{MPa}\end{array}$ & $\begin{array}{c}\text { Deformation } \\
(\mathrm{mm})\end{array}$ & $\begin{array}{c}\text { Stress } \\
(\mathrm{MPa}\end{array}$ & $\begin{array}{c}\text { Deformation } \\
(\mathrm{mm})\end{array}$ \\
\hline $\begin{array}{c}\text { Full load } \\
\text { bending }\end{array}$ & $\begin{array}{c}239.2 \\
8\end{array}$ & 4.855 & $\begin{array}{c}191.6 \\
2\end{array}$ & 15.189 \\
Torsional & 412.0 & 15.985 & $\begin{array}{c}387.5 \\
7\end{array}$ & 19.331 \\
Emergency & 352.6 & 6.715 & 320.5 & 16.476 \\
brake & 4 & & 9 & \\
Emergency & 302.8 & 13.335 & 472.2 & 38.228 \\
steering & 4 & & 8 & \\
\hline
\end{tabular}

We compare the stress and deformation of the bus frame under four conditions which is shown in Table 4. The results manifest that transferring the battery to the chassis and reducing the weight of the roof can effectively reduce the stress and deformation. In addition, thickening the beam which is used to support the air suspension can increase the strength of the beam minimizing the possibility of being destroyed.

\section{Conclusion}

In this study, we use FEA method to analyze the static force on the bus frame under four driving conditions. Then we optimize the structure of the bus by reducing the crosssectional width of the frame on the bus roof. We also remove the reinforcing ribs on the roof. It is believed that this research project can provide a profound understanding of using FEA for the application of lightweight of an electric vehicle.

\section{Acknowledgement}

This project is supported by Premier-Discipline Enhancement Scheme Supported by Zhuhai Government Fund (2015YXXK14).

\section{Reference}

1. M. Weiss, P. Bonnel, J. Kühlwein, A. Provenza, U. Lambrecht, S. Alessandrini, et al., "Will Euro 6 reduce the NOx emissions of new diesel cars?Insights from on-road tests with Portable Emissions Measurement Systems (PEMS)," Atmos. Environ., vol. 62, pp. 657-665, (2012).

2. P. Bielaczyc, J. Woodburn, and A. Szczotka, "An assessment of regulated emissions and $\mathrm{CO} 2$ emissions from a European light-duty CNG-fueled vehicle in the context of Euro 6 emissions regulations," Applied Energy, vol. 117, pp. 134-141, (2014).

3. U. Tang and Z. Wang, "Influences of urban forms on traffic-induced noise and air pollution: Results from a modelling system," Environ. Model. Software, vol. 22, pp. 1750-1764, (2007).

4. F. Pan, P. Zhu, and Y. Zhang, "Metamodel-based lightweight design of B-pillar with TWB structure via support vector regression," Computers \& structures, vol. 88, pp. 36-44, (2010).

5. F. Lan, J. Chen, and J. Lin, "Comparative analysis for bus side structures and lightweight optimization," Proc. Inst. Mech. Eng. Pt. D: J. Automobile Eng., vol. 218, pp. 1067-1075, (2004). 